\title{
Undisclosed creators of digitalization: A critical analysis of representational practices
}

\author{
Katarina L. Gidlund* and Leif Sundberg \\ Mid Sweden University, Sundsvall, Sweden
}

\begin{abstract}
The aim of this paper is to study over- and under representational practices in governmental expert advisory groups on digitalization to open up a dialogue on translations of digitalization. By uncovering how meanings converge and interpretations associated with technology are stabilized or maybe even closed, this research is positioned within a critical research tradition. The chosen analytical framework stretches from technological culture (i.e., how and where the myths and symbolic narratives are constructed), and a focus on the process of interpretation (i.e., the flexibility in how digitalization could be translated and attached to different political goals and values) to a dimension of firstness (addressing education, professional experiences and geographical position to explore dominance and power aspects). The results reveal a homogeneity that is potentially problematic and raises questions about the frames for interpreting what digitalization could and should be and do. We argue that the strong placement of digitalization in the knowledge base disclosed in this study hinders digitalization from being more knowledgeably translated.
\end{abstract}

Keywords: Digitalization, digital government, representational practices, technological culture

\section{Key points for practitioners:}

- The results highlight the importance of balance in between knowledge bases (for example educational background and professional work experiences) due to a more multi-dimensional understanding of digitalization (as a counterweight to the often one-dimensional policy narrative of digitalization as just artefacts).

- The results underpins the importance of an enhanced awareness of when exclusive and/or inclusive practices are performed, i.e. earlier and not only in the user-centered design situations, but on a policy level as well since it effects the translations of digitalization and societal change that informs digitalization doings.

- The methodology can be used to achieve a broader representation of knowledge bases among the actors participating in policy making and as such the output in terms of translations and policies become less one-dimensional.

\section{Introduction}

Digitalization is a widespread concept that is frequently present in public debate and policy documents in relation to a diverse range of societal issues, from trade unions (Kirov, 2017) to public service broadcasting (Donders and Pauwels, 2008). On the European, national and regional levels, digital agendas are created to define our possible digital future (European Union, 2010). More seldom do we direct our attention to 'by whom' digitalization is narrated and try to disclose the contexts in which they are enacting and performing digitalization. In 2009, Wiebe E. Bijker argued that the most pressing question is not what technology is but how technology is made (Bijker, 2009). In continuation, "constructivist studies

\footnotetext{
${ }^{*}$ Corresponding author: Katarina L. Gidlund, Mid Sweden University, Holmgatan 10 SE-85170 Sundsvall, Sweden. E-mail: katarina.1.gidlund@miun.se.
}

1570-1255 (C) 2021 - The authors. Published by IOS Press. This is an Open Access article distributed under the terms of the Creative Commons Attribution-NonCommercial License (CC BY-NC 4.0). 
of technology thus do not primarily answer the question 'what is technology?'; they trace the process of "how technology is made" (Bijker, 2009, p. 63). Against the background of 10 more years of what could be labeled as a massive diffusion of a not very critically disentangled digitalization discourse, the question of the making of technology is as topical as ever.

In this text we argue, in line with Bijker, that to achieve a deeper understanding of digitalization (as a narrative and construct), we need to unveil different types of aspects of how it is made, particularly with a critical approach due to the often utilized idea of digitalization as an empowering transformative phenomenon empowering the many, not only the few (which, for example, the UN's Human Development Report 2019 analyzes on the national and regional levels).

Against this backdrop, the purpose of this paper is to study over- and under representational practices in governmental expert advisory groups on digitalization in order to enhance the possibilities to open up a dialogue on translations of digitalization. By doing so, we dig deeper into "the who and the how" of how digitalization is made (i.e., the practices of digitalization narration and, as such, targeting a specific practice: the policy-making and governmental advisory boards).

The empirical case is government expert advisory groups. These groups are supposed to provide advice to the government and contribute to the story of digitalization through, for example, public reports on future scenarios and policy recommendations, but they are seldom subject to scrutiny. They are not decision makers in a strict sense (see e.g., Selling \& Svallfors, 2019), and they are thus seldom held accountable for the effects of the future scenarios and guidance they give. However, at the same time, their view on digitalization receives much attention and credit, and they are described as champions and evangelists of digitalization. They perform interpretations, notes, and writes and communicates expert advice in press releases and reports, but the question who inhabits the expert advisory board is an elusive matter to traverse Bijker, Bal and Hendriks' text on the role of advice in democracies (Bijker et al., 2009). The political use of expert knowledge has been studied in other contexts, such as immigration policy (Boswell, 2009), public health (Bijker et al., 2009), or in terms of discursive legitimation and strategic knowledge claims in education (Maton, 2000) but not in relation to hopes entangled with digitalization. This despite the fact that only in Europe a vast amount of financial support is directed to efforts in the digitalization area. In 2018, additionally 9.2 billion euros were directed as a part of the European digital market (European Union 2015), justified with hopes of a return of 415 billion euros per year (European Commission, 2018).

In this study the phenomenon of expert advisory groups is studied from a representational perspective, where overr- and underrepresentation are touched upon in relation to positions that are given legitimacy to translate the phenomenon of digitalization. This is in line with Bijker's argument that we need to expose experts to "show that other readings are possible" (Bijker, 2001, p. 24), which also resonates with to how certain norms are reproduced and others are omitted, and Feenberg's discussion on dominant and subordinate subject positions (Feenberg, 2012:x). Where subordinate subject positions "encounter technology as a dimension of their lifeworld, for the most part they merely carry out the plans of others or inhabit technologically constructed spaces and environments" and is thus far more complex than that of dominant actor. Dominant subject positions, or masters, on the other hand are more aligned with an orientation towards reality based on technical, financial and engineering logics ("rational planning to a world reduced to raw materials", Feenberg, 2012:x).

By studying expert advisory groups, we expect to highlight whether the story of digitalization runs the risk of being told from a base that is too narrow and as such being closed too soon and if there might be potential in a more open and inclusive narration. Since digitalization often is depicted as a global phenomenon that penetrates most areas of society, we argue that it is important to provide a context to the 
dominant narratives that are reproduced in, for example, government documents and by doing so, open up for sub-narratives.

This paper proceeds as follows. First, the theoretical positioning and analytical framework is explained (Section 2); next, the operationalization of the analytical framework in methodological terms is presented (Section 3). Then, the results (Section 4) and analysis sections (Section 5) follow. Finally, the contribution to the understanding of digitalization practices concludes the paper (Section 6).

\section{Analytical framework}

The analytical framework is primarily inspired by philosophy of technology, which addresses and demystifies the relation between technology's essence and construct. By doing so, the narratives of digitalization at the policy level are made empirically available (Feenberg, 2000). By questioning the interpretations of digitalization and its place in the world, and in the policies, the depersonalization of power in deterministic theories are dealt with to some extent. The point of departure is that these policies produce narratives of digitalization that show a certain orientation towards reality, highlighting certain aspects and downplaying others. In line with Feenberg, we argue that this is not only an orientation, but also an action in the world, and so it becomes a construct. Or as Feenberg (2000) puts it: "they are not fantasies, obviously, or there would be no effective technologies" (Feenberg, 2000:232). Essentialist insight into the technical orientation toward the world is as such combined with constructivist insights into the social nature of technology and how certain stories are incorporated into the social world of technical production in specific spaces. Our scientific philosophical basis is as such an interplay in between ontological stances (what kind of orientation towards reality digitalization carries and performs) and constructivist perspectives (how these orientations than takes shape and embodiments). The main argument for this analysis is that the orientation(s) towards the world quickly transforms "constraints into taken-for-granted internal technical specifications" (Feenberg 2000:235) that determine technical code and performations and frame institutional and individual action space.

As Vanderburg argues, "perhaps the time has come to revisit the fundamental question of our responsibilities for our technological creations," and he continues by criticizing both deterministic and constructivist perspectives of ignoring the inseparability of "thoughts and action from lives, lives from communities, and communities from their historical journeys" (Vanderburg, 2012, p. 331). According to Vanderburg, we need to focus on the relationship between a society and its technology in terms of analyzing the symbolization and myths of technology by culture-based and discipline-based approaches (i.e., paying attention to how the authority of technology translation is performed and by what kind of knowledge base). Otherwise, we will find ourselves in a society where the hierarchy between culture and technology is gradually reversed and "the triumph of everything digital is comprehensive" (Vanderburg, 2012, p. 336).

The chosen analytical framework stretches from technological culture (i.e., how and where the myths and symbolic narratives are constructed), and a focus on the process of interpretation (i.e., the flexibility in how digitalization could be translated and attached to different political goals and values) to overand under-representation in order to address dominant and subordinate subject positions. However, even though we in this paper utilize a set of categories to explore imbalances in representational practices it is, in line with Gonick and Hladki (2005), important to state that these categories are not presented as only information but as beginnings for critical inquiry. As such, we struggle with the tensions between naming categories as a device for further analysis and the acknowledgement of the ways in which they have real material effects on people's lives. It must also be declared that we are not completely comfortable with 
representation as a concept, at least not when it is used at the individual level claiming that one carries one's representation and is expected to perform in relation to it (Sefyrin et al., 2013). In this paper, the focus is therefore not on the specific individuals but on the individual professional identities as subjects to individuals as carriers and mediators of discursive practices and structures (Barad, 2007). With such a standpoint, the independent subject is not the study object; instead, they are seen as being produced by and reproducing - the practices of which they are part (see e.g. Wenger, 1998). Consequently, there are no detached or independent entities which are, or can be, represented. Instead, these subjects and objects are produced by a variety of representational practices, and it is through these practices that power and exclusionary practices are exercised in relation to defining what is being represented (Sefyrin et al., 2013, Sefyrin \& Gidlund, 2014). This signifies that the categories that are often used for representation (such as the number of women in steering committees) are seen as formed within dominant practices and power relations through the application of boundaries that include and exclude. The study object is then the practices and how they are performed, who and what fall outside and who and what do not fit into any category at the center of attention (Butler, 2011a, 2011b).

Finally, we argue that these representational practices need to be confronted in some way, and to do so, we use the concept of "firstness" by Brade (2015). Firstness is put forward by Brade as an "empty analytical category applicable to a range of power relations in flexible and context-specific ways" (Brade, 2015:172): it highlights underexposed positions, in this context, the ones (the first) that are expected to know digitalization instead of the ones (the others) that are constantly asked to develop 'digital competence'. In this context, there are many studies discussing those who are not digitally literate, digitally mature or digitally skilled (Van Deursen \& Van Dijk, 2011; Van Dijk \& Van Deursen, 2014), but few studies critically explore the reference point: those considered digital experts.

By studying "the first," there is potential for a better understanding of why the others are reproduced by a sense of oddness, differentness, exceptionality and departures from the norm (Brade, 2015). However, when we talk about "the others", we do not explicitly refer to the aforementioned digital divides, which have been covered relatively well by prior research, especially in relation to classic demographic categories such as age, social status etc. Our attention is on the position that constitutes the norm of how digitalization should be understood: those given the expert advisory title by the government in order to create awareness of why others might appear 'odd' in relation to the first. We therefore theoretically link the first and the others to dominant or subordinate subject positions as discussed by Feenberg (2012). The dominant subject position is, according to Feenberg, technological masters "who relate through rational planning to a world reduced to raw materials". A subordinate subject position "strive to appropriate the technologies with which they are involved and adapt them to the meanings that illuminate their lives. Their relation to technology is thus far more complex than that of dominant actors" (Feenberg, 2012: xi). By linking the first and dominant subject position, and the other and subordinate subject position, a possiblity to enter a dialogue of closures and openings in digitalization narrative constructs unfolds.

In this paper, the critical analysis of representational practices is devoted to exploring who is given the unquestioned position of expert on digitalization. This strict focus on firstness, we argue, might help with generating a fundamental understanding of how both digitalization and otherness (i.e., the non-experts on digitalization) might be constructed. To study the representational practices, we have chosen to analyze categories related to the professional role of the experts, together with their geographical residence, alongside with gender. These categories will be further motivated and described in the next section. Analytically, we use Bijker's (1995) "democratization of technological culture" and the argument that no a priori social group should be prioritized in the development of technology: instead, all groups are considered symmetrical. This principle of symmetry can be used to detect asymmetries in the 


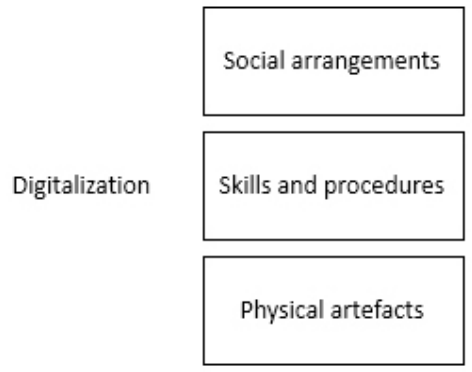

Fig. 1. The three dimensions of digitalization (inspired by Winner, 1977).

technological development. In line with Pinch and Bijker (1984), we argue that the social groups (in our case, appointed experts on digitalization) involved in the making of technology (including policy making), will affect its trajectory.

As explained by Pinch and Bijker (1984, pp. 68-69), technology is associated with an interpretative flexibility; different interpretations and translations of what for example an artifact "is", that can be linked to relevant social groups. However, this flexibility is often subject to a process of stabilization, where one or more dominant social groups have the privilege to determine what the technological artifact "is". This process may lead to a state of closure where the interpretative flexibility has collapsed, in favor of dominant translations. An important task for research is to identify why processes of stabilization followed a certain path, rather than another. By studying translations, we are able to identify possibilities for openings, and giving voice to alternative narrative constructs. Since digitalization often is depicted as a global, social-wide phenomenon, we argue that it is vital to investigate the mechanisms that may lead to stabilization, or even closure of how the term is interpreted. Hence, in this paper, the analysis is made from the view that digitalization is about more than just technological devices, that it is about profound societal change and as such it is even more important to critically examine the preferences of the interpreters.

As mentioned in the introduction, "digitalization" is a seldom defined concept (Brennen and Kreiss, 2014), and to discuss the representational practices of digitalization, we not only need to use frameworks in relation to representation but also an outline of how we use the concept of digitalization. For this purpose, we use the theoretical framework by Winner (1977) with three types or dimensions of technology (Fig. 1): technology as apparatuses (physical artefacts), technology as techniques (skills and procedures) and technology as organizations or institutions (social arrangements). Digitalization could therefore be understood as physical digital objects or artefacts (smartphones, computers and fiber), digital techniques (digital case management, digital payment techniques or digital learning platforms) and societal arrangements (re-arrangements of societal institutions in a digital age such as work, identity and nation state).

Digitalization is not only defined as the practices closely linked to creating "technical machines" or machine-like processes of production. According to Winner's definition of technology, digitalization could be understood as the digital things, or artefacts, we create but also as the procedures and skills we develop. In Winner's terminology, technical skills and procedures are technology as techniques. To further describe the 'skills and procedures' dimension, we can draw upon Andrew Feenberg's critical inquiry of technology in which the initial understanding of technology was that it is something that should be useful, or it would not be considered to belong to the phenomenon of technology (Feenberg, 2003). Digitalization then also features a dimension of skills and procedures creating useful results and techniques to create usefulness. According to Winner, the third dimension, social arrangements, is closely related to "social 
organization," how we organize, for example, factories and bureaucracies, but it could also be further developed by addressing institutional aspects (i.e., how we organize other social institutions such as the government, work, economy, families and education). These three dimensions are related to, but not equivalent to, Bijker's 'units of analysis' (Bijker 2009). To a certain degree the expert advisory groups could be seen as 'relevant social groups'. However, they are not linked to a singular technical artefact, but to the idea of technological culture or ensembles, or in Feenberg's conceptualization, 'orientation towards reality'.

\section{Empirical material and methodological choices}

As mentioned in the introduction our focus in this study is the idea of national governmental expert advisory groups (Information Technology (IT) commissions, digital councils or digital commissions) that are expected to give advice and guide political work. We argue that these types of expert advisory groups are interesting from three aspects: 1 . They are given credit as experts, translators and storytellers of digitalization, and could as such be seen as given a formal dominant position in terms of interpretative prerogative. 2. Since they are formally chosen to represent expertise when the group is formed by the central government, the composition matter and the composition says something about what fields of knowledge are seen as valuable, and not 3 . The expert advisory groups are not held accountable as politicians but are given an independent position even though they give both advice and take part in policy making. As Bijker stresses, much effort is invested in an effective 'landing' of the advices of these kinds of expert advisory groups, "in repairing misinterpretations, and in advocating the intended message- in other words, in policy-making effectiveness" (Bijker, 2012:18).

We have chosen to study these groups from two different angles: we are both investigating positions to disclose dominant or subordinate representational practices among the expert advisory groups, and patterns in, and surrounding, the final reports these groups have produced as narrative constructs. The analysis is performed by expressing the composition of the expert groups (nine groups, 136 experts) in quantitative terms through descriptive statistics based on the chosen categories and by interpreting their stories through content analysis of seven final reports. Our argument for mixing these two approaches is in order to, as Bijker points out, provide characteristics to the 'by whom-question' at the same time as providing insights to what they are producing i.e. the content of the reports. However, as stressed in the analytical framework section we struggle with representation as a concept, at least when it is used at the individual level claiming that one carries one's representation and is expected to perform in relation to it (Sefyrin et al., 2013). In this paper, the focus is therefore not on the specific individuals but on the individual professional identities as subjects to individuals as carriers and mediators of discursive practices and structures (Barad, 2007). Our interest here is in the composition of categories chosen by government and what the composition might disclose in relation to valuable knowledge and practical experiences.

By studying categories related to the professional and educational occupation among these experts, our intention is both to disclose "the first" and at the same time address "the others" and discuss the imbalance in between the two. The reason we focus on categories related to professions is due to these being highlighted in prior research, but understudied in the relation to digitalization policies. The professional role involves a certain set of competences and constitute a domain where participants learn from each other, but also restricts the set of means that the professional uses to solve a problem (see, Wenger 1998, and Nordin 2000, also, Kuhn, 1970). However, few studies have studied representational practices in the form of professions in relation to policy documents on digitalization, which is the research gap we aim to fill in this paper. 


\subsection{Expert groups}

The case chosen here is the Swedish expert advisory groups. During 1994-2003 four IT commissions consisting of external experts were led by a minister (the prime minister, coordination minister, communication minister and enterprise minister, respectively). The model of relying on external experts continued, independent of the political leaning of the government, as evidenced by the IT political strategy group of 2003-2006 and the government's IT council of 2007-2010. The first expert group with the word "digitalization" in its name was established in 2011, the Digitalization Council, and was replaced by the Digitalization Commission in 2012. This commission was replaced by yet another Digitalization Council in 2017. We have chosen to focus on the expert advisory groups but also upon the construction, the placing and the stories created during the different constructions.

Methodologically, the material was gathered by tracing the members (who are openly declared on government websites) and thereafter searching for a number of categories (on the government websites but also complemented by open searches on LinkedIn and social media such as Facebook); the members emerged as study objects for further analysis. News articles and archived websites were also used to create an initial map of the experts and their characteristics.

As previously stated, the purpose of this paper is to study over- and under representational practices in governmental expert advisory groups on digitalization to open up a dialogue on translations of digitalization. By doing so, we expect to be able to discuss what these traits (here analysed as categories) imply in terms of the performance of boundaries that include and exclude, who and what fall outside and who and what do not fit i.e. are there under- or over-representations that will be illustrated by the analysis of categories.

The empirical material consists of over 20 years of national digitalization advisory boards in Sweden during the period of 1994-2019, and 136 members were mapped. To map the experts, the following categories were used: gender, educational background, education location and geographical residence.

- Gender was divided into male/female (no other categories were identified in the material).

- To categorize educational background, a standard for research fields from the Statistics Sweden agency (2020) was used. It contains three levels, and for the purpose of this research, we used the second level as per the example below: Social Sciences $\rightarrow$ Economics and Business $\rightarrow$ Business Administration.

- Educational location was based on the university's name and geographical location (city).

- Geographical location was based on the Swedish counties $(n=21)$.

The results consist of descriptive statistics, which are then interpreted with the chosen analytical framework to critically examine not the individual subjects but what the representational practices produce, reproduce, include and exclude.

\subsection{Final reports}

By adding contextual factors about the expert advisors, we have also performed studies of organizational structure, positioning and stories in terms of the choice of responsible minister, directive, and final reports. The final reports are only briefly analyzed in this article (a more thorough discourse analysis is planned for the future). As additional empirical material, the organizational structure and positioning in relation to ministries are accounted for, and the reports produced in line with the expert advisory groups are briefly analyzed. These are returned to after the first analysis of dominant traits and analyzed in relation to the findings of the first phase. 
Table 1

Expert advisory groups in Sweden

\begin{tabular}{|c|c|c|}
\hline Expert group and period & Responsible minister and directive & Final report \\
\hline The IT commission 1994-1995 & Prime minister $\mid$ No formal directive & $\begin{array}{l}\text { "IT - Wings to the ability of man" (IT- } \\
\text { kommissionen, 1994). }\end{array}$ \\
\hline The IT commission 1995-1996 & $\begin{array}{l}\text { Coordination minister (Regeringen } \\
\text { 1995) }\end{array}$ & $\begin{array}{l}\text { Input into the "Actions to broaden and de- } \\
\text { velop the use of IT" (Regeringen, 1996:2) } \\
\text { strategy. }\end{array}$ \\
\hline The IT commission 1996-1998 & $\begin{array}{l}\text { Communication minister (Regeringen } \\
\text { 1996:1) }\end{array}$ & $\begin{array}{l}\text { "New times, new conditions" (IT- } \\
\text { kommissionen, 1998). }\end{array}$ \\
\hline The IT commission 1998-2003 & Enterprise minister (Regeringen, 1998) & $\begin{array}{l}\text { "Digital services - How?" (IT- } \\
\text { kommissionen, 2003). }\end{array}$ \\
\hline $\begin{array}{l}\text { The IT political strategy group } \\
\text { 2003-2006 }\end{array}$ & $\begin{array}{l}\text { Infrastructure minister (Regeringen, } \\
\text { 2003) }\end{array}$ & $\begin{array}{l}\text { "Politics for the IT society" (Regeringens } \\
\text { IT-politiska strategigrupp, 2006). }\end{array}$ \\
\hline $\begin{array}{l}\text { The government's IT council 2007- } \\
2010\end{array}$ & $\begin{array}{l}\text { Infrastructure minister (Regeringen, } \\
\text { 2007) }\end{array}$ & No final report \\
\hline $\begin{array}{l}\text { The Digitalization Council 2011- } \\
2012\end{array}$ & $\begin{array}{l}\text { IT and energy minister (Regeringen, } \\
\text { 2011) }\end{array}$ & $\begin{array}{l}\text { Input to the "IT in the service of } \\
\text { man - A digital agenda for Sweden" } \\
\text { (Regeringskansliet, 2011) strategy. }\end{array}$ \\
\hline $\begin{array}{l}\text { The Digitalization Commission } \\
2012-2016 \text { (members replaced after } \\
\text { the } 2014 \text { election) }\end{array}$ & IT minister (Regeringen, 2012) & $\begin{array}{l}\text { "For digitalization - in time" (Digitaliser- } \\
\text { ingskommissionen, } 2016 .\end{array}$ \\
\hline The Digitalization Council 2017- & $\begin{array}{l}\text { Housing and digitalization minister } \\
\text { (Regeringen, 2017) }\end{array}$ & \\
\hline
\end{tabular}

The end products of the expert investigations are often published in the form of an "SOU". An SOU is a public investigation by a committee, appointed by the central government, to use as a basis for political decision making (Statens Offentliga Utredningar, 2020). The final reports of the expert groups ( $n=$ 7 , some of the groups have not published a report) are subject to thematic content analysis based on Winner's aforementioned three dimensions of technology (physical artefacts, skills and procedures, and social arrangements). By interpreting the content of the reports through these three dimensions, we expect to be able to further scrutinize implications in relation to what traits are found (and missing) in the expert groups.

\section{Results}

The presentation of the results beings with the contextual descriptive material with the contextual descriptive material of organisational structures and positioning the expert advisory groups are acting within and around. Thereafter we will focus upon what the categories reveal in terms of homogenous patterns of whom the government give legitimacy to by appointing them expert advisor. Lastly, the final reports are given account for with the ambition of unveiling the strategies, consensus-oriented images and their underpinnings.

\subsection{Organizational structures and positioning}

As background material, we added organizational constructions (Table 1). Before presenting the results in relation to the different categories, Table 1 demonstrates how digitalization has traveled in between responsible ministers, regarding at which ministry digitalization is placed, directives and focus regarding final reports. The organizational structures and positionings add to the results from the study of the members because they tell a story of what digitalization is seen as adding value to or being related to. 


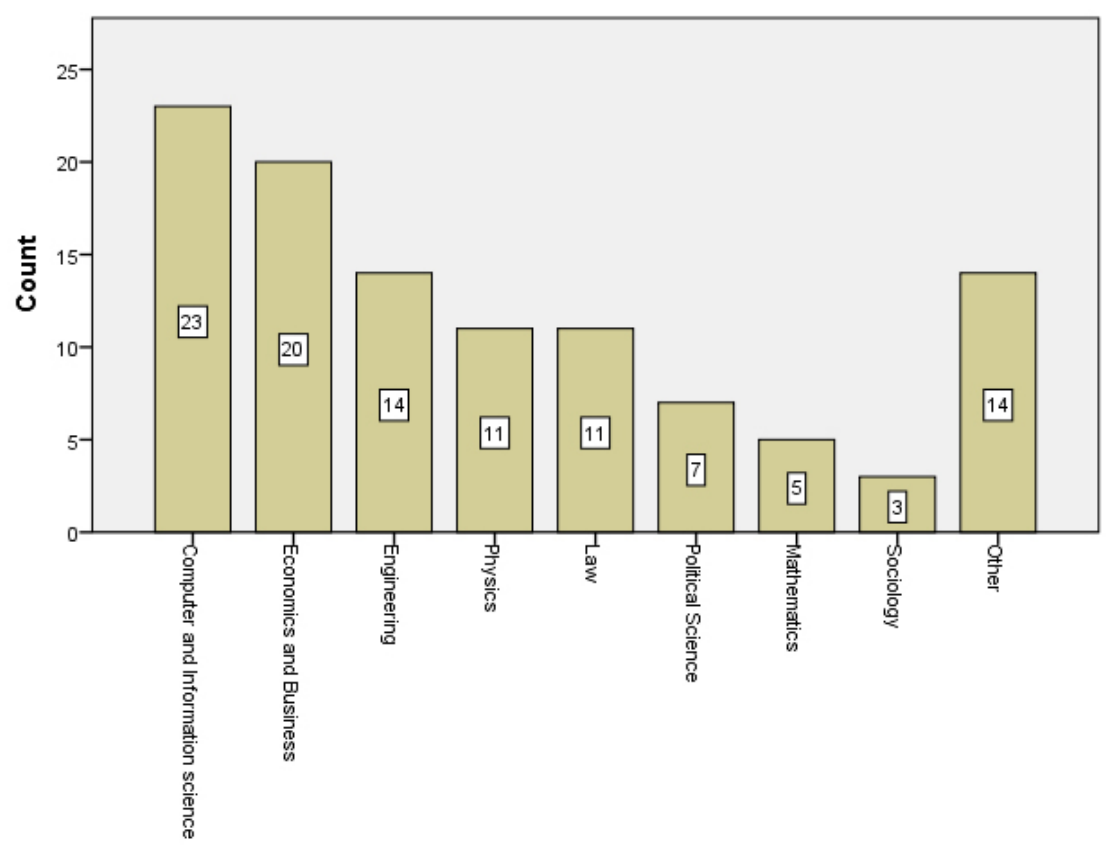

Fig. 2. Educational background.

The different ministries hold different expert knowledge, both among the employees and as descriptive demarcations of the focus of the ministry. By placing digitalization in a specific ministry, certain expert knowledge is available, and certain areas and values are focused upon. As such, the placement itself tells a story of how digitalization is translated and understood. For example, after the millennium shift the responsible minister for IT and digitalization has resided within the ministry of enterprise, and thereafter within the ministry of infrastructure.

\subsection{Gender}

As mentioned in Section 3, the material in this study consists of 136 experts on IT and digitalization. Of the 136 experts, 66 are female, and 70 are male. When we compared gender to the other categories, only two major differences were found: in the first expert group (the IT commission), 10 experts are male, and three are female. In the latest group (the second digitalization council), six experts are male, and nine are female. In one of the educational backgrounds, namely law, 10 of the 11 experts are male, and one is female. No major differences were found depending on the government's political alignment (traditional left or right). When the government advisory groups on digitalization were constructed, there seemed to be an awareness of gender bias. However, as is demonstrated in the following, there are other strong dominances that might overshadow the gender category.

\subsection{Educational background}

Regarding educational background, there proved to be a strong dominance of two educational backgrounds (see Fig. 2, missing data $=28$ ). Experts in the top of the material are computer- and information science $(n=23)$ and economics and business with 20 experts. We merged the engineering educations, 


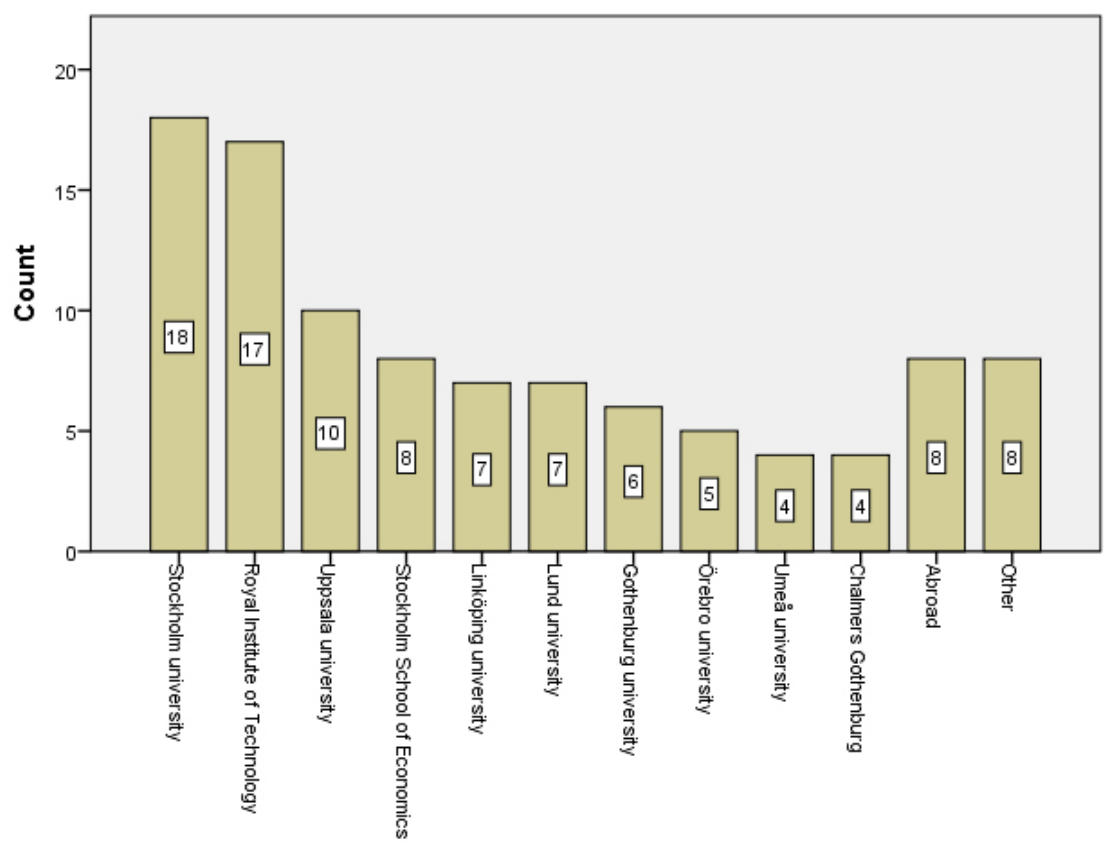

Fig. 3. Education location.

which comes in third place with 14 experts. When comparing expert groups with "IT" in the name to the groups with an emphasis on "digitalization," the percentage of computer scientists stayed roughly the same, while the experts on economics and business increased from 5.6 to 25 valid percent.

On the one hand, it might seem obvious that when addressing issues of digitalization, it is necessary to include competencies related to how digital solutions are made (i.e., computer and information science and engineering) and how digital solutions could generate economic value (i.e., economics and business). On the other hand, competencies on societal development and societal challenges (such as humanities including sociologists and welfare professions such as education, health care and librarians where there is a strong pressure for digital transformation) could be said to be equally important in translating what type of values digitalization should create and what type of societal challenges are pressing from a socially sustainable development perspective.

\subsection{Education location}

To further disseminate the educational background, we have also used education location as a category for disclosing socializing patterns based on the idea that not only what type of professional training but also in what context the training has been given might have an effect (e.g., on future social networks and future employment). Figure 3 reveals that Stockholm is the most common education location for members of the expert advisory groups; 45 out of 102 (missing $=34$ ) experts have a degree from one of the universities in the capital, with Stockholm University and Royal Institute of Technology in the top two positions.

The result indicates a dominance regarding where the expert advisors cultivated their professional social networks, in and around Stockholm $(18+17+8+2$ from "other" $=45 / 102[34$ missing] $=44$ valid percent). These universities are also large universities with many students; however, Lund University 


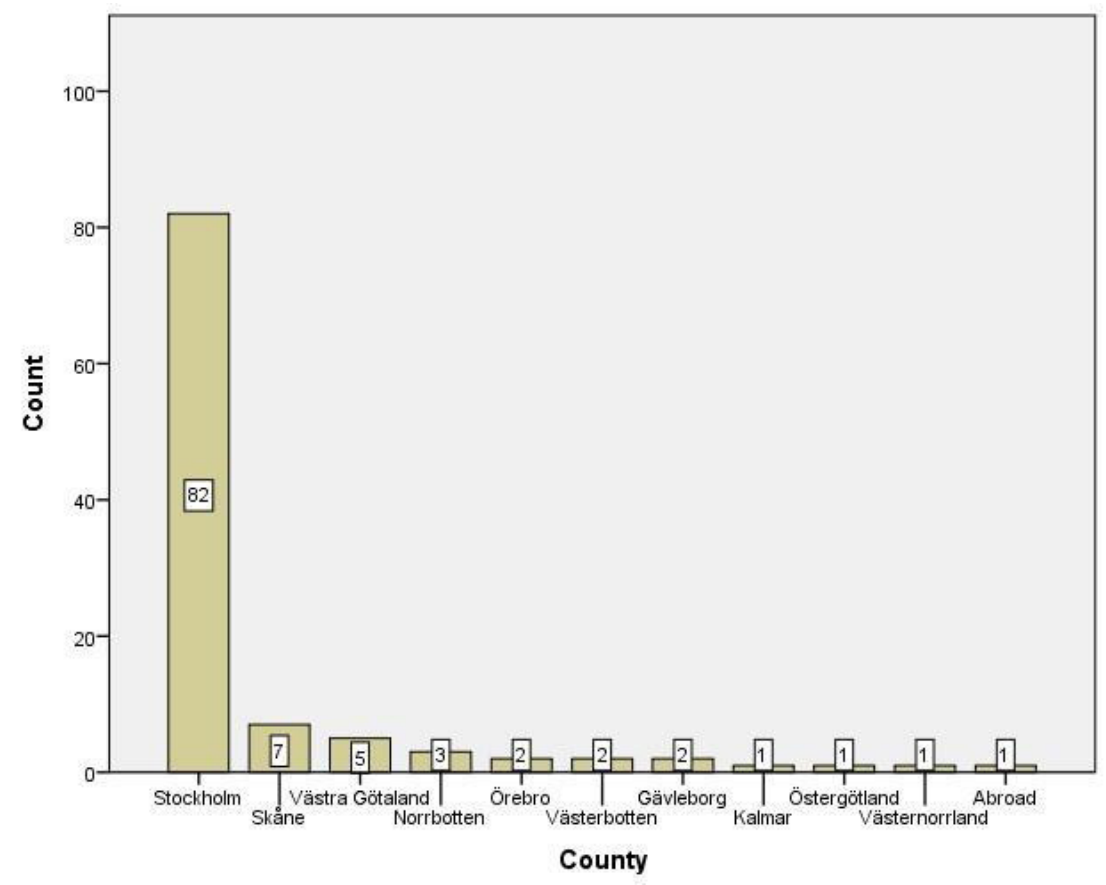

Fig. 4. Geographical residence.

and Gothenburg University are as well, so there is more to it than that Stockholm University and Royal Institute of Technology (and Uppsala University) are large. These universities are also all situated in a geographically narrow space. This narrowness is interesting from a social constructivist perspective on how discourses are developed, and as such, this category is also a start to the geographical aspects of relevant social actors.

\subsection{Geographical residence}

As stated above, the result of the education location category highlights the geographical aspects of socializing (networking and shared material experiences), so the geographical residence becomes even more interesting since it not only indicates whether the experts stayed in the geographical contexts they developed during their professional training, but it also says something about their professional context while acting as an expert.

To determine the geographical residence, we used counties. Sweden consists of 21 counties. As displayed in Fig. 4, Stockholm clearly stands out, with 82 out of 107 experts (missing = 29). For comparison, about $20 \%$ of the Swedish population lives in the county of Stockholm. In second and third place, with 7 and 5 experts respectively, are Skåne and Västra Götaland. These counties contain the second largest cities in Sweden after the capital: Malmö (third largest city in Sweden) and Gothenburg (second largest city in Sweden). As visible in Fig. 4, there is a clear dominance of Stockholm-based experts $(n=82)$. Compared to the expert groups on IT, the number of experts that reside in Stockholm increased from $64.4 \%$ to $85.5 \%$ (valid percent) after the terminology shifted to digitalization.

Not only did a large portion of the experts receive their professional training in and around Stockholm, when chosen to be part of the government expert advisory groups, an even larger portion of them resided 
in Stockholm. Geographical location and residence turned out to be interesting in terms of analyzing if there are some common characteristics inside the group and some relevant characteristics left out that would significantly influence the shared understandings.

\subsection{Final reports}

Digitalization (as "IT" in the 1990s) began at the prime minister's table and then traveled to be of concern for coordination and communication ministers. Around the turn of the millennium, there was a shift into enterprise and infrastructure, which has dominated since. The first IT commission, which was established under the prime minister in 1994, had no formal directive but had the task of promoting the broad use of IT as a means to increase quality of life and Sweden's international competitiveness. In their final report (IT-kommissionen, 1994), IT is described as a convergence of technologies "tele, data, text, audio, television, cable- and radio" (IT-kommissionen, 1994:29) (physical artefacts), and as a tool, which, if used correctly, "gives wings to the ability of man" (by enabling, revolutionizing, and transforming conditions for nations and individuals = disrupting social arrangements in a beneficial way, if used correctly). Like subsequent documents, this report emphasizes the importance of a broad range of actors utilizing IT, and a range of areas where IT is especially important is listed, such as education and research, the justice system, the government, health care and enterprises.

The second IT commission was given the formal directive (Regeringen, 1995) of promoting a broad use of IT, with a special focus on enterprises, work life, education and competence. A large part of their work was dedicated to assisting in the formulation of a 1996 IT proposition (Regeringen, 1996:2), which was accepted by parliament. The proposition established a range of goals for when Sweden enters the knowledge and information society: growth, employment, competitiveness, knowledge, competence, justice, equality, welfare, participation, preservation of the Swedish language and culture and efficiency and quality in the public sector. Furthermore, IT is described as a driving force that entails structural changes in society, including the convergence of technologies and sectors.

The third IT commission received similar directives as their precursor, with additional focuses on growth and employment, the availability of IT independent of sociodemographic status and the investigation of possible future scenarios (Regeringen, 1996:1). Their end report describes an upcoming knowledge society, which approaches in a rapid pace, based on Internet-based technology, in which IT is described as an enabler (IT-kommissionen, 1998). The common denominator in the reports from the first three IT commissions is the idea of a future (knowledge- or information) society that revolves around IT: IT is a tool, or an enabler of transformation in most areas of society, with an emphasis on economic growth. If broad support is gained, the fast development toward the new society is accompanied by almost endless opportunities. However, individuals and organizations that fail to see how IT may affect them will experience "difficulties" (see e.g., IT-kommissionen, 1997). Hence, the first three IT-commissions put a large emphasis on social arrangements: the establishment of a (new) society which revolves around the use of IT in the broadest sense of the word.

The fourth IT commission was assembled in 1998 with the directive to analyze IT's impact on social development (Regeringen 1998). This expert group was active for 5 years and presented their final report in 2003. Between the reports of the third and fourth IT commissions, the IT industry survived the year 2000 bug but was affected by the dot-com crash. The content in the final report from the fourth IT commission describes a nation struggling in the aftermath of economic recession. Investments in IT are described as necessary in the long term due to the need for cost savings in, for example, the public sector. This report focuses on the digital service society, in which human functions are automated using 
IT (IT-kommissionen, 2003). One way of interpreting this report is that the idea of a new technological society had been slightly smeared, and the content slightly shifted towards discussing how physical artefacts (such as "broadband") in combination with certain skills and procedures (transition to services) could generate benefits and combat the economic recession.

The successor to the four IT commission was named the IT Political Strategy Group. Their directive (Regeringen, 2003) included promoting a political goal from 2000 (Regeringskansliet, 2000): that Sweden, as the first nation in the world, should become an information society for everyone. The content of their final report (with the goal of creating an "IT-society") includes visions and recommendations in a range of areas such as economic growth, environmental sustainability, health care, education, culture and democracy. Key factors for IT to make an impact in these areas are coordination, availability (including bridging digital divides), trust, infrastructure, and legal adaptions (Regeringens IT-politiska strategigrupp, 2006).

The IT Political Strategy Group was replaced by an IT council in 2007. Their directive (Regeringen, 2007) expresses a focus on trade and industry. This expert group did not produce a final report. The rather short-lived successor, the Digitalization Council, was given the directive of exchanging opinions and experiences and contributing to the work of a digital agenda (Regeringen, 2011), which was released in 2011 (Regeringskansliet, 2011). The digital agenda for Sweden revolves around the goal of Sweden becoming the greatest nation in the world in utilizing the opportunities of digitalization. While the idea of becoming a prominent digital nation was mentioned by the prime minister as early as 1994, it now became an official goal in a policy. Hence, after a small regression after the burst of the IT bubble, the idea of a new, technological society was once again emphasized in government documents. However, the terminology surrounding the technology shifted: the "new" societal arrangements presented in reports and policies at the time shifted from IT to "digitalization".

A digitalization commission was established in 2012 to ensure that the digital agenda was implemented in line with the government's ambitions (Regeringen, 2012). Their end report (Digitaliseringskommissionen, 2016) describes digitalization and new technology as engines in the development of a data-driven society, in which all sectors of society are affected. Digitalization may enable a "previously inconceivable" democratic and sustainable welfare society. The Digitalization Commission describes:

We have gone from IT to digitalization, from cables and hardware to societal development in a broad meaning. We have gone from a focus on technology, to a focus on the human; this is good, and necessary. (Digitaliseringskommissionen 2016, p. 7).

The Digitalization Commission (Digitaliseringskommissionen, 2016) describes the digital transformation (digitalization is referred to as a "transformative force" comparable to the notion of IT in (Regeringen 1996:2) as rapid due to processes such as globalization, urbanization and individualization, which demand adaptation and flexibility. The report includes a discussion of international indexes to benchmark the goal from the digital agenda. Moreover, the potential effects of digitalization (positive and negative) are discussed, including a scenario describing Sweden in 2030. The report highlights four recommendations: the establishment of a government agency to promote digitalization (an agency for digital government was established in 2018), the formulation of a strategy for digitalization (a national digitalization strategy was published in 2017), strengthening the leadership for digitalization and a strong emphasis on (digital) competence to enable welfare and economic growth in the digital society. Thus, a link is established between skills and procedures (= digital competence), necessary to build and maintain the depicted societal arrangements ( $=$ the digital society). 
A digitalization council was established in 2017 with directives to coordinate digitalization issues and to implement and develop strategies in the Ministry of Industry (Regeringen, 2017). This group is still active and has not yet released a final report.

As mentioned above, a shift from IT to digitalization occurred around 2011 through the digital agenda. Before that, the optimism associated with IT had been slightly smeared following the dot-com crash. Although digitalization was mentioned in the 1990 reports as well, it then took over the role IT had before the millennium shift: a convergence of technologies with potential disruptive effects in a future data-driven society. Although the name for this future society shifted during the studied period, it is described as being driven or enabled by technology. Even if the new technology might be a choice (the formulation shifts between describing digital technology as a force, or a tool, which is presented as an obvious choice): those who do not choose it (e.g., vulnerable groups) will experience difficulties, as will Sweden as a nation, unless we adapt to the rapid transformation with an emphasis on education and (digital) competence. Notable in the material is that, even though several of the aforementioned experts have a background within computer science, it is interesting that we find very few stories about physical artefacts in the final reports generated by these groups.

\section{The first and the odd}

Throughout this study a critical standpoint has been a guiding principle, and the ambition is to uncover how meanings converge and interpretations associated with digitalization are stabilized, or maybe even closed. The chosen analytical framework stretches from technological culture (i.e., how and where the myths and symbolic narratives are constructed), and a focus on the process of interpretation (i.e., the flexibility in how digitalization could be translated and attached to different political goals and values) to a dimension of firstness (addressing education, professional experiences and geographical position to explore dominance and power aspects). By directing the attention to those given the position as and legitimized by the government as experts, we argue that we could learn about how certain translations of digitalization are reproduced and how others are omitted. By studying "the first," we both gain insight into what type of representational categories one is expected to fit into to be chosen as an expert but also why those who were not chosen might be reproduced by a sense of oddness and departures from the norm (Brade, 2015).

The results describing over 20 years of advisory work in digitalization matters proved to be interesting. The dominant trait is that digitalization is translated through the eyes of Stockholm-based managers with disciplinary competence in IT, economics and engineering from universities situated in and around Stockholm. Furthermore, digitalization has often been understood as an area for enterprise and infrastructure ministries, and in the shift from IT to digitalization, economic issues and Stockholm-based experts surfaced. Are these results then important in some way? Do the results indicate something we would otherwise oversee if we did not follow up on government expert advisors?

Our focus, as declared in the introduction, was to study over- and under representational practices in governmental expert advisory groups on digitalization to open up a dialogue on translations of digitalization. These groups were studied from a representational practices perspective in terms of homogeneities and exclusion. As stressed by Vanderburg we cannot separate "thoughts and action from lives, lives from communities, and communities from their historical journeys." (Vanderburg, 2012:331). We must focus on the relationship between a society and its technology in terms of analyzing the symbolization and myths of technology by culture- and discipline-based approaches. 
In this case, it is obvious that a glance at the lives and communities of one of the relevant social groups provides a deeper understanding of how technological cultures are made. As Bijker points out, "different relevant social groups have their specific kinds of expertise - we are all experts in specific ways" (Bijker, 2001:31). In this study it is shown that digitalization is described through the eyes of, to a large extent, a homogenous group. This unification gives not only a shared learning in terms of the fact that their professional identity is co-created in their experiences in their community, but it, at the same time, runs the risk of being configuring (i.e., that one adjusts to a certain view of what digitalization is and is not). As such, there is a risk of closure and hardening of what type of story may be told about digitalization. The interpretations could be accused of being "too few" and "too narrow" and that this gives that some aspects of historical contextuality and materiality are omitted. We argue that this homogeneity is problematic, and it raises questions about how it is interpreted what digitalization could be, and should do.

If the stories of digitalization in governmental reports are translated through "the eyes of Stockholmbased managers with disciplinary competence in IT, economics and engineering from universities situated in and also around Stockholm" and also produced by public officers at ministries of enterprise and infrastructure, the story of digitalization runs the risk of being told by what Feenberg might call "technological masters", discursively legitimating certain orientations towards reality and not others. Bijker has argued that there is more to a technological culture than what is "described in engineers' handbooks" (Bijker, 2001:32), and other experts need to be involved "in the whole design process in an as early a stage as possible" (Bijker, 2001:32). The results indicate a reproduction of digitalization as a phenomenon primary translated and understood by "technological" and economical competencies based on what could be labeled as industrialization (i.e., the optimization of production processes). As Bijker states, relevant social groups (or experts) are socialized into translating technological culture within certain norms (through undergraduate training, through social networks during undergraduate training, etc.), and in this case, digitalization could be said to be dominated by these two disciplines, whereas others are in minority. It thus appears as if the educational background within governmental experts as a relevant social group is interesting for further study. These findings can be contrasted to digitalization in the public discourse where it is often conjoined with challenges the minority (or even missing) professions are experts on. The results from this study indicate that there exists a 'relevant social group' translating the concept of digitalization that might need to be broadened in order to gain a more comprehensive and inclusive knowledge base for understanding digitalization. We argue that the strong placement of digitalization in the knowledge base disclosed in this study hinders digitalization in being more knowledgeably translated.

Continuing with the analysis of structure, positioning and the final reports the document study reveal that the stories of both IT and digitalization revolves around the idea of a "new" information-, knowledge, or digital, society. For the past two decades, these narratives have been generated from the ministries of enterprise, and the ministry of infrastructure where the IT and digitalization ministers have resided. Hence, the dominating dimension in the material is social arrangements, expressed in the form of this new society. However, the final reports stem contexts (enterprise, infrastructure, engineering, computer and information science, engineering, economics) where the anticipated expertise would relate to the other two dimensions (e.g. engineers and physical artifacts). The absence of professional backgrounds that specializes in human and societal conditions (e.g. the humanities) becomes problematic, especially when the reports emphasize that digitalization is distinguished from IT by a "move" from physical artifacts to social arrangements.

Taken together and analyzed with the backdrop of the analytical framework resting on Winner's three dimensions (arrangements, skills, and artifacts) what becomes evident and interesting is that the social dimensions of digitalization are present in the translations, but made by "the first" and expected to be 


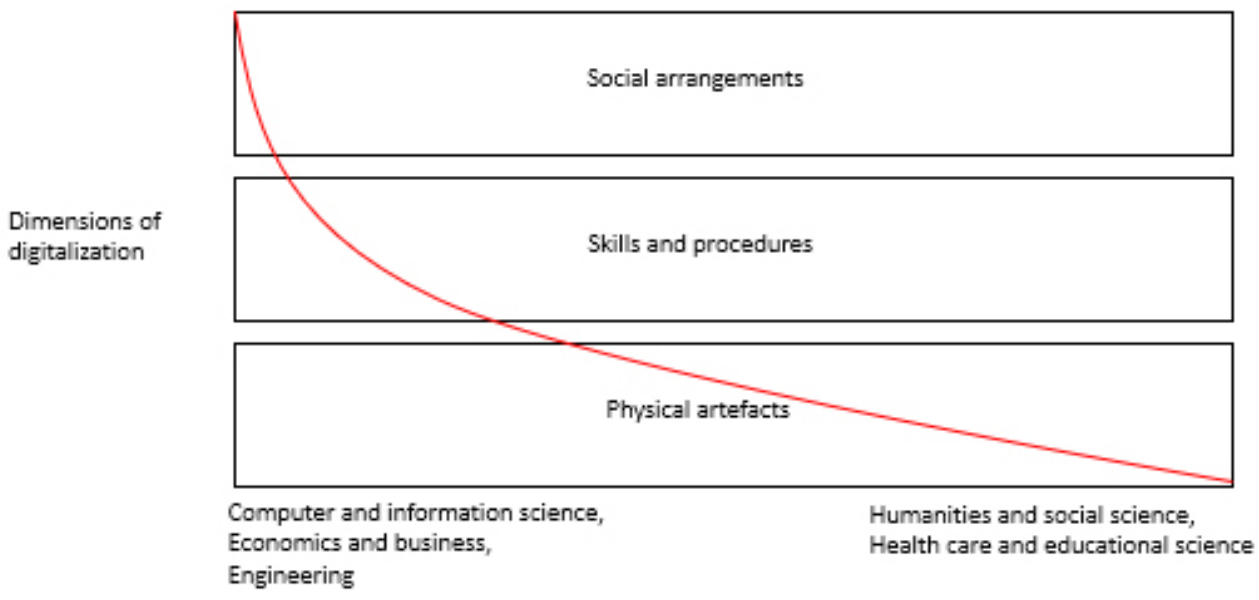

Fig. 5. The three dimensions of digitalization (inspired by L. Winner).

realized by "the others" (the not represented). As such the result highlights Feenberg's comment on the different positions in relation to technological development where some are masters and others are to carry out the plans made by the masters and tries to inhabit the constructed spaces and environments (Feenberg, 2012) of the policies on digital futures.

To prevent digitalization being subject to closure through narrow interpretations made by the dominant social groups identified in this paper, we argue that the translations could be different if they were made by those professionally skilled and educated within other knowledge bases. Examples of such areas could be elderly care or education, where many large investments in digital technology are made. Other actors absent in the studied material are experts on ethics that reside in the humanistic disciplines (e.g. philosophy, theology, sociology). We argue that it is problematic when these knowledge bases are largely absent in texts that depict the (good) digital society.

This is also where the theoretical conceptualization of digitalization by Winner (1977) could illustrate and question the firstness indicated in this study. If digitalization holds more than the physical artifact and efficiency-oriented skills dimension (illustrated by the added line in the Fig. 5), other representational categories are missing and instead being translated as oddness, differentness and departures from the norm. For example, the translation of digitalization made by, rural-based care givers instead of urban-based engineers.

This line of reasoning also illustrates that with a wider perception of digitalization government issues related to the topic could have been placed at another ministry: for example, at the Ministry of Justice or the Ministry of Social Affairs. Instead, narratives with a heavy focus on social arrangements, are being told from ministries responsible for enterprise and infrastructure, and by experts on technology and economy.

As our findings reveal, to use Bijker's terminology, the balance between dimensions and dominant homogeneities are highly asymmetrical and we would like to raise the question what possible effects this asymmetry might lead to. With a different setting other inscriptions in terms of narratives, written and spoken words, images and arguments of 'why and how' digitalization and configurations, and how we experience the performances of digitalization, would be possible. 


\section{Conclusion and future research}

The purpose with this paper was to study over- and under representational practices in governmental expert advisory groups on digitalization to open up a dialogue on translations of digitalization. The purpose was achieved by directing our attention to who narrates digitalization, and by disclosing the contexts in which they are acting and performing digitalization to demonstrate how certain norms might be reproduced and others omitted. The concept of firstness by Brade highlights the importance of investigating those granted positions and those "the others" are compared to and expect to relate to. As Brade has stated, by studying the first, we can gain an understanding of why the others are reproduced as odd or different and positioned as subordinate and as such far more complex. "The first" are given interpretative preference and "the others" are given the position of carrying out the "plan of" the first in a Feenbergian logic. But we would also like to add that by doing so, demarcations taken for granted are opened, and other translations are invited. The analysis was not only of representational practices and hierarchical positions in relation to the translation of digitalization, but it also illustrated that the concept of digitalization becomes almost one-dimensional or naively three-dimensional, when stories about a digital society are told from a narrow range of norms. By addressing the making of digitalization as made above, by uncovering the doings by whom, a platform for dialogue comes into sight where seldom unproblematized firstness can be questioned and challenged.

In future research, it would be interesting to investigate in an exploratory manner what would happen if "the odd" were given the opportunity to translate digitalization into a firstness manner but also to explore how "the first" describe their firstness, if at all.

\section{References}

Barad, K. (2007). Meeting the universe halfway: Quantum physics and the entanglement of matter and meaning. Duke University Press.

Bijker, W. E. (1995). Democratisation of technological culture. Inaugural speech, University of Maastricht.

Bijker, W. E. (2001). Understanding technological culture through a constructivist view of science, technology, and society. Visions of STS: Counterpoints in science, technology and society studies, 19-34.

Bijker, W. E. (2009). How is technology made? - That is the question! Cambridge Journal of Economics, 34(1), 63-76.

Bijker, W. E., Bal, R., \& Hendriks, R. (2009). The paradox of scientific authority: the role of scientific advice in democracies. MIT press.

Boswell, C. (2009). The political uses of expert knowledge: Immigration policy and social research. Cambridge University Press. Brennen, S. \& Kreiss, D. (2014). Digitalization and digitization. Culture digitally. Digitalization and Digitization.

Brade, L. H. (2015). "Just So You Know; I'm Absolutely Completely Normal!" - An Empirical Investigation of Firstness. NORA-Nordic Journal of Feminist and Gender Research, 23(3), 170-186.

Butler, J. (2011). Gender trouble: Feminism and the subversion of identity. Routledge.

Butler, J. (2011). Bodies that matter: On the discursive limits of sex. Routledge.

Digitaliseringskommissionen. (2016). SOU 2016:89: För digitalisering i tiden. Näringsdepartementet.

Donders, K. \& Pauwels, C. (2008). Does EU policy challenge the digital future of public service broadcasting? An analysis of the Commission's state aid approach to digitization and the public service remit of public broadcasting organizations. Convergence, 14(3), 295-311.

European Commission (2018). Digital Europe Program. https://ec.europa.eu/commission/presscorner/detail/en/IP_18_4043.

European Union (2010). A Digital Agenda for Europe, ISBN 978-92-7941904-1.

European Union (2015) A Digital Single Market Strategy for Europe.

Feenberg, A. (2003) What is Philosophy of Technology? Lecture for the Komaba undergraduates, 2003

Feenberg, A. (2012). Questioning technology. Routledge.

Human Development Report 2019, by the United Nations Development Programme, 1 UN Plaza, New York.

IT-kommissionen. (1994). SOU 1994:118: Informationsteknologin: Vingar åt människans förmåga. Statsrådsberedningen.

IT-kommissionen. (1997). SOU 1997:63: Sverige inför epokskiftet. Kommunikationsdepartementet.

IT-kommissionen. (1998). SOU 1998:65: Nya tider, nya förutsättningar. Kommunikationsdepartementet. 
IT-kommissionen. (2003). SOU 2003:55: Digitala tjänster - hur då? En ITpolitik för resultat och nytta. Näringsdepartementet. Kirov, V. (2017). Digitalization of Public Services in Europe: Policy Challenges for the European Trade Union Movement. In Policy Implications of Virtual Work, Palgrave Macmillan, Cham, pp. 251-272.

Kuhn, T. S. (1970). The structure of scientific revolutions. University of Chicago Press, Chicago.

Nordin, I. (2000). Expert and non-expert knowledge in medical practice. Medicine, Health Care and Philosophy, 3(3), 295-302.

Pinch, T. J. \& Bijker, W. E. (1984). The social construction of facts and artefacts: Or how the sociology of science and the sociology of technology might benefit each other. Social Studies of Science, 14(3), 399-441.

Regeringen. (1995). Dir. 1995:01. Kommissionen för att främja en bred användning av informationsteknik.

Regeringen. (1996:1). Dir. 1996:46: Tilläggsdirektiv till Kommissionen (1995:01) för att främja en bred användning av informationsteknik.

Regeringen. (1996:2). Åtgärder för att bredda och utveckla användningen av informationsteknik.

Regeringen. (1998). Dir. 1998:38: Kommissionen för analys av informationsteknikens påverkan på samhällsutvecklingen IT-kommissionen.

Regeringen. (2003). Den IT-politiska strategigruppens direktiv (N2003/4799/ITFoU).

Regeringen. (2007). Arbetsgrupp med uppgift att tillhandahålla råd i IT-politiska frågor (N2007/5698/ITP).

Regeringen. (2011). En rådgivande grupp för IT-frågor (N2011/1944/ITP).

Regeringen. (2012). Digitaliseringskommissionen - en kommission för den digitala agendan (2012:61).

Regeringen. (2017). Inrättande av ett råd med uppgift att främja genomförande av den allmänna digitaliseringspolitiken (N2017/01899/D).

Regeringens politiska strategigrupp. (2006). Politik för IT-samhället.

Regeringskansliet. (2000). Regeringens proposition 1999/2000:86 Ett informationssamhälle för alla.

Regeringskansliet. (2011). IT i människans tjänst - en digital agenda för Sverige. Näringsdepartementet.

Regeringskansliet. (2017). För ett hållbart digitaliserat Sverige - en digitaliseringsstrategi.

Sefyrin, J., Gidlund, K. L., Öberg, K. D. \& Ekelin, A. (2013). Representational practices in demands driven development of public sector. In International Conference on Electronic Government, Springer, Berlin, Heidelberg, pp. 200-211.

Sefyrin, J. \& Gidlund, L. K. (2014). Inscriptions of norms, values and hegemonies on different technological levels. Proceedings of STS conference in Graz 2014: Critical issues on science and technology studies.

Selling, N. \& Svallfors, S. (2019). The lure of power: Career paths and considerations among policy professionals in Sweden. Politics \& Policy, 47(5), 984-1012.

Statens Offentliga Utredningar (2020). Frågor och svar om kommitteer. Retrieved June 2020 from: https://www.sou.gov.se/fragoroch-svar-om-kommitteer/.

Statistics Sweden. (2020). Standard för svensk indelning av forskningsämnen. Retrieved June 2020, from: https://www.scb.se/ dokumentation/klassifikationer-och-standarder/standard-for-svensk-indelning-av-forskningsamnen/.

Van Dijk, J. \& Hacker, K. (2003). The digital divide as a complex and dynamic phenomenon. The Information Society, 19(4), 315-326.

Van Deursen, A. \& Van Dijk, J. (2011). Internet skills and the digital divide. New Media \& Society, 13(6), 893-911.

Van Dijk, J. A. \& Van Deursen, A. J. (2014). Digital skills: Unlocking the information society. Palgrave Macmillan.

van Deursen, A. J. \& van Dijk, J. A. (2015). Internet skill levels increase, but gaps widen: A longitudinal cross-sectional analysis (2010-2013) among the Dutch population. Information, Communication \& Society, 18(7), 782-797.

Van Laar, E., Van Deursen, A. J., Van Dijk, J. A., \& De Haan, J. (2017). The relation between 21st-century skills and digital skills: A systematic literature review. Computers in Human Behavior, 72, 577-588.

Vanderburg, W. H. (2012). The autonomy of technique as a social and historical description: Our failure to exercise our responsibilities by digitizing life and surrendering it to computers. Bulletin of Science, Technology Society, 32(4), 331-337.

Wenger, E. (1998). Communities of practice: Learning as a social system. Systems Thinker, 9(5), 2-3.

Winner, L. (1977). Autonomous Technology: Technics-out-of-control as a Theme in Political Thought. Cambridge (Mass.)

Bijker, W. E., Hughes, T. P., \& Pinch, T. (2012). The social construction of technological systems: New directions in the sociology and history of technology (Anniversary ed.).

Feenberg, A. (2000). From essentialism to constructivism: Philosophy of technology at the crossroads. Technology and the Good Life, 294-315.

Feenberg, A. (2003). Modernity theory and technology studies: Reflections on bridging the gap. Modernity and Technology, 73.

Gonick, M., \& Hladki, J. (2005). Who are the participants? Rethinking representational practices and writing with heterotopic possibility in qualitative inquiry. International Journal of Qualitative Studies in Education, 18(3), 285-304.

Maton, K. (2000). Languages of legitimation: The structuring significance for intellectual fields of strategic knowledge claims. British Journal of Sociology of Education, 21(2), 147-167.

Vaj Dijk \& Hacker (2003) finns i reflistan men ej i texten. 